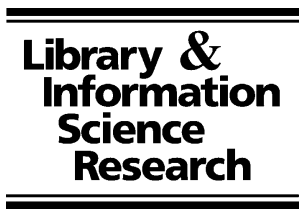

\title{
Motivations and uses: Evaluating virtual reference service from the users' perspective
}

\author{
Jeffrey Pomerantz*, Lili Luo
}

School of Information and Library Science, University of North Carolina at Chapel Hill, CB 3360, 100 Manning Hall, Chapel Hill, NC 27599-3360, USA

\begin{abstract}
The questions of whether chat reference service is beneficial enough to users to justify the costs of offering it, and how valuable it is to users in fulfilling their information needs, have been primary concerns for librarians providing the service, for library administrators managing the service, and for funding agencies paying for it. The present study combines a traditional evaluation of the user's satisfaction with the reference encounter, with details of the user's information use and the user's motivation for using the chat reference service. This evaluation study assesses the effectiveness of chat reference service in meeting users' information needs.
\end{abstract}

(C) 2006 Published by Elsevier Inc.

\section{Introduction}

With the increasing availability of computers and Internet access both within libraries and in modern society at large, online services have become among the most heavily used services libraries offer. Chat reference is one such service enabled by computing and networking, the use of which is increasing. The implementation, management, and evaluation of chat reference service have attracted much attention from library practitioners and researchers over the past several years. The questions of whether chat reference is beneficial enough to users to justify the costs of offering it, and how valuable it is to users in fulfilling their information needs, have been primary concerns for librarians providing the service, for library administrators managing

\footnotetext{
* Corresponding author.

E-mail addresses: pomerantz@unc.edu (J. Pomerantz), luolili@email.unc.edu (L. Luo).
} 
the service, and for funding agencies paying for it. Evaluating chat reference services from the users' perspective, and exploring users' feedback on their use of the service, constitutes one solution to gauge the value and utility of the information provided by such a service to users.

Library reference service, whether at the desk, by asynchronous media such as e-mail, or by synchronous media such as chat, is generally provided in an interactive setting that involves two parties, the librarian and the user. Evaluations of the success of a reference transaction have therefore traditionally taken into consideration the points of view of both of these parties: the quality of the answer provided by the librarian and the user's satisfaction with this answer and other aspects of the reference encounter. Both of these evaluation metrics are useful for evaluating a reference service; it is necessary both that answers provided by a service be accurate and complete, and that the user be satisfied. These evaluation metrics are limited, however, in that they assess the outcome of the reference interaction immediately following its conclusion. These metrics are concerned with a single point in time and do not look backwards or forward in time: neither has the ability to identify what information need brought the user to the service in the first place, or to assess the user's use of the information provided and its impact over the long term.

This methodological limitation is in part an artifact of reference work traditionally being performed at a desk: once a user leaves the library, it is difficult or impossible to follow-up to ask about her use of the information provided. With the advent of virtual reference services, however, it became possible to follow-up with the user, as in this type of service the user is asked to provide an e-mail address. This made it possible to get in touch with users some time after they obtained answers to their questions to determine the use to which they put this information. Even given this, however, few studies of virtual reference services have investigated user's uses of the information provided by the service, or identified the information needs that give rise to the user's question to the service.

The present study combines a traditional evaluation of the user's satisfaction with the reference encounter, with details of the user's information use and the user's motivation for using the chat reference service. This combination of methodologies may serve as a model for the evaluation of other virtual reference services, in combination with other evaluation methods and metrics. The goal of this evaluation study was to assess the effectiveness of chat reference service in meeting users' information needs. This was addressed by the investigation of three research questions:

1. What is the users' level of satisfaction with chat reference service?

2. What motivates users to use chat reference service?

3. How are users using the information provided by chat reference service?

This study was conducted in the context of the collaborative statewide service chat-based reference service NCknows (www.ncknows.org). NCknows was launched for an 18-month pilot phase in February 2004. Nineteen libraries participated in the pilot phase, and librarians in all nineteen of these libraries staffed the service during the pilot. These libraries included public, research university, community college, and government libraries and spanned the state to include urban $\lambda_{\lambda}$ and rural, $\lambda_{\lambda}$ arge; and small libraries. The NCknows project was started with 
funding from an Institute of Museum and Library Services (IMLS) Library Services and Technology Act (LSTA) grant and is coordinated by the State Library of North Carolina's Library Development Section (statelibrary.dcr.state.nc.us). The pilot phase of NCknows has been completed, and in July 2005 the service had its final launch. ${ }^{1}$

\section{Literature review}

Evaluation of chat reference services is important, given the mixed response that such services have received, from both librarians and users. Coffman and Arret (2004a, 2004b), for example, discuss the failure of many commercial reference services, and question whether chat is a viable medium for offering library-based reference service. Horowitz, Flanagan, and Helman (2005), for another example, describe the rise and fall of a chat reference service offered by the Massachusetts Institute of Technology's libraries. Given that the viability of chat reference for libraries has still not been definitively established, it is essential for libraries offering chat reference services to evaluate the service.

Metrics for the evaluation of reference services fall into two broad categories, defined by the perspective taken on the service: from the point of view of the user, and from the point of view of the service itself. Saxton and Richardson (2002), in their review of the many measures that have been used in the evaluation of library reference services, refer to these perspectives as the "obtrusive user-oriented approach primarily concerned with testing for levels of user satisfaction with the service," and the "query-oriented approach primarily concerned with testing the accuracy of answers to reference questions" (p. 33). In addition to answer accuracy, other metrics from the service perspective include the size of the library's collection, the resources used in the answer, and the cost of the service (Murfin, 1993), among others.

Two approaches to evaluating reference service from the user's point of view have traditionally been employed: obtrusive and unobtrusive. Obtrusive evaluation employs observation of the reference transaction, so that both the user and the librarian know that they are being observed. Unobtrusive evaluation is a "secret shopper"-style methodology where the researcher or a proxy asks a question as a user, so that the librarian does not know that he or she is being observed. Crowley (1971) made the first recorded use of unobtrusive evaluation, and this method has been employed for many reference evaluations since (Dewdney \& Ross, 1994; Durrance, 1989; Ross \& Nilsen, 2000; Weech \& Goldhor, 1982). Though all of these data collections were anonymous, it was possible for the researchers to collect data some time subsequent to the reference transaction only because the proxies were known and available to the researchers.

Although proxies have been employed in evaluations of digital reference services (Kaske \& Arnold, 2002), it is not necessary to do so because it is possible to elicit data from the user and still maintain an unobtrusive methodology. This is accomplished through the use of an exit survey that the user fills out upon completion of the reference transaction. Exit surveys have

\footnotetext{
${ }^{1}$ More libraries around the state have joined the project since the conclusion of the pilot phase. The list of participating libraries can be found on NCknows' Web site.
} 
been utilized for evaluations of e-mail reference services: Pomerantz (2004) describes surveys that studied users' satisfaction with the AskERIC e-mail service and the composition of the AskERIC user population. Exit surveys are more common, however, for evaluations of chat reference services (Hill, Madarash-Hill, \& Bich, 2003; Marsteller \& Neuhaus, 2001; Ruppel \& Fagan, 2002). Immediately following the reference transaction is the easiest, and perhaps the only, time to collect data from the user of a digital reference service: the user is "present" at that moment, and once the user disconnects from the service may be difficult or impossible to contact her to collect more data. Although it may be possible to contact a user of a digital reference service after the conclusion of the reference transaction (via the user's e-mail address), this is rarely done.

The use of a reference service from the users' perspective may be broken down temporally into three stages: prior to the use of the service, during and immediately following the use of the service, and subsequent to the use of the service. Scriven uses the term evaluand to refer to "that which is being evaluated" (Scriven, 1991, p. 139). Thus, three evaluands may be posited within the timespan of a user's use of reference a service: the user's motivation for using the service, the user's perception of the service, and how the user uses the information provided by the service.

These three evaluands correspond to the three stages of an individual's movement through a situation, as posited in Dervin's theory of sense-making (1983). Dervin suggests that the ultimate goal of a user's search for information is to bridge a gap between her internal cognitive state and external reality in order to make sense of the world in addressing some issue or concern in her life. The gap is the core premise of sense-making theory: Dervin (2003) posits that "discontinuity is an assumed constant of nature generally and the human condition specifically" (p. 271), which unavoidably places a gap between one's internal world and external reality. This gap provides the underlying motivation for the user to seek information from an external source. Bridging this gap provides the motivation for the user to use particular information sources. How the information helped (or hurt) the user to bridge that gap may reflect on the source that provided that information. One such information source may be another person, in the form of a librarian in a virtual reference service.

There have not been many studies that examine users' motivations for using library reference services. Among the few studies that have interviewed library users concerning their motivations for using library services in general, Marchant (1991) explored the motivations for adults' use of public libraries and categorized these motivations as being derived from four major life interests: family life, vocational growth, religion, and politics. Saracevic and Kantor (1997) concluded that users' reasons for using library services fall into three categories: for a task or a project; for personal reasons; and to get an object, information, or perform an activity. It is reasonable to assume that the information needs that motivate use of a library-based virtual reference service would fall into the same categories that motivate use of library services in general.

Mitchell (1982) defines motivation as "the degree to which an individual wants and chooses to engage in certain specified behaviors" ( $p$. 82), which can be further divided to two categories: intrinsic and extrinsic. Intrinsic motivation refers to "a drive arising within the self to carry out an activity whose reward is derived from the enjoyment of the activity itself" 
(Davis \& Wiedenbeck, 2001, p. 554). Extrinsic motivation refers to external incentives and rewards that motivate an individual to perform an activity (Shapira, Kantor, \& Melamed, 2001). For this study, motivation is characterized as either intrinsic or extrinsic, both of which drive the user to seek information. An example of an intrinsic information need is personal curiosity; an imposed query, defined by Gross (1999) as a question from an individual seeking information on behalf of another person, is an example of an extrinsic information need.

Whether and how a users' information need has been satisfied by using an information service may be taken as indicators of both the value of the service and the utility of the information provided by the service. Variables of information value and utility measurement include affective results, accomplishment of information tasks and changes in work performance, mental and physical effort expended in searching information, and monetary value (Broadbent \& Lofgren, 1993; Saracevic \& Kantor, 1997; Su, 1992). In studies examining these variables, users were interviewed and surveyed immediately following their use of an information service; this particular time constraint, however, only allows for collection of data of the perceived value of the information to the user. Users had not yet had a chance to apply the information in solving their problems. What has been missing in these studies is a more realistic elicitation of user's valuing of information, that is, how users actually use information to address concerns or solve problems.

Information use is defined here as the real life utility value of information for the user. This value is taken as an indicator of NCknows' success in providing help that fulfills users' information needs. Ahituv (1980) studied three approaches to valuing information. One of these is the "realistic value" approach, which attempts to measure the impact of information on the outcomes of decisions and the performance of decision makers before and after gaining the information. This approach has been adopted by the present study to allow users to comment on how they used the information provided to them by NCknows to solve problems that arose from the situations in their life, in an effort to analyze how users' information needs have been fulfilled.

\section{Methodology}

Two distinct methods were employed to collect data at different stages of the process of users' use of the NCknows service and the information provided to them. First, an exit survey popped up for the user at the conclusion of a chat session. NCknows uses the 24/7 Reference application to provide chat service (www.247ref.org). The exit survey was implemented using the functionality of the software itself: when the user left the chat session by clicking on the Exit button, the exit survey popped up. Unfortunately if the user left the session in some other way - by closing the browser window, or if the browser crashed, of if technical problems cut the chat session short - the exit survey would not pop up.

The exit survey created for this study did not pop up for users who came into the NCknows service through the Public Library of Charlotte \& Mecklenburg County (PLCMC)'s queue. Instead, at the conclusion of chat sessions, PLCMC's users received the default exit survey provided by the $24 / 7$ Reference company to their customers. This was 
the case because PLCMC had a contract with 24/7 Reference, separate from the rest of NCknows, due to the fact that PLCMC launched their chat reference service in February 2002, two years prior to NCknows' launch. To have the exit survey created for this study pop up for PLCMC's users would have required a separate negotiation between the evaluation team, PLCMC, and 24/7 Reference, which was unfeasible at the time that this data collection effort was launched. PLCMC is the largest contributor to NCknows' volume of chat sessions, accounting for $43 \%$ of NCknows' total volume. Thus, a large percentage of NCknows' users were not surveyed for this data collection effort. This will not be an issue in future evaluations of NCknows, however, as PLCMC did not renew their individual contract with 24/7 Reference, and instead joined the contract between NCknows and 24/7 Reference as of February 2005.

The drawback of creating a customized exit survey, however, is that the exit survey responses were not automatically linked to chat session transcript numbers, which functionality is available to services that do use 24/7 Reference's default exit survey. The research team was able to manually link most (70\%) of the exit survey responses to chat session transcript numbers. This linking was performed using two criteria: the date and time of the chat session and the submission of the exit survey, and comparison of the e-mail addresses that users provided to the NCknows service at login and on the exit survey. If a user did not provide an e-mail address either at login or on the exit survey, sometimes transcripts could be linked using the date and time alone. The $30 \%$ of exit surveys that could not be linked to transcripts were those for which this was impossible. The NCknows service has, since the conclusion of this evaluation effort, gone back to using 24/7 Reference's default exit survey, precisely so that this linking is performed automatically.

The questions on the custom exit survey designed for this study were derived from Hirko (2004) and McClure, Lankes, Gross, \& Choltco-Devlin (2002), both of whom make recommendations for measures that may be collected when performing evaluations of digital reference services. These sources are based on both best practice and the American Library Association's guidelines (2004) for providing digital reference service. ${ }^{2}$

The second method to collect data on users' use of the NCknows service was semistructured interviews with NCknows users. The final two questions on the exit survey ask if the user was willing to be contacted for a follow-up interview, and for his or her e-mail address. If the user was willing to be contacted, the researchers sent the user an invitation e-mail, asking to set up a telephone interview. This e-mail message also contained the text of the interview questions, so that the user would have advance knowledge of the questions that the researchers would ask. This message was sent to the user two weeks after their chat session because this amount of time was judged to be long enough for the user to have applied the information obtained from NCknows but short enough for the user to still have a clear memory of the chat session. A time for a telephone interview was set up by e-mail; these telephone interviews therefore took place two to three weeks after the user's chat session. The interviews consisted of five questions. Two primary types of data were collected in these interviews: users'

\footnotetext{
${ }^{2}$ The exit survey can be found online at: http://purl.oclc.org/NET/POMERANTZ/NCKNOWS/exitsurvey.html.
} 
motivation for using the NCknows service and how users used the information provided to them. ${ }^{3}$

\section{Results}

From March through November 2004, a total of 4563 users submitted questions to the NCknows service, not via PLCMC's queue. Out of these, 392 users $(8.6 \%)$ submitted the exit survey, and 284 users (6.2\% of all users, $72.4 \%$ of users who submitted the exit survey) indicated willingness to be contacted. Of the users willing to be contacted, $73(25.7 \%)$ replied to the invitation e-mail and answered the interview questions either in a telephone interview or by e-mail. A total of 24 telephone interviews were conducted and 49 e-mail responses were received. These low response rates raise the issue of the effect of unit non-response bias on these results, which will be discussed below.

\subsection{Prior to use of the service}

\subsubsection{Use of other reference services}

A total of 67 users answered the question in the follow-up interviews whether they had ever used any of the other reference services offered by their library. Of these above respondents: ${ }^{4}$

- 48\% (32) had used their library's desk reference service,

- $19 \%$ (13) had used the e-mail reference service,

- $33 \%$ (22) had used the telephone reference service,

- 19\% (13) had never used any other reference services,

- 7\% (5) did not answer the question directly, and

- $7 \%$ (5) were librarians or library staff.

The purpose of this question was to determine if NCknows users were the same individuals who used other library reference services, or if NCknows was reaching new user communities. The results indicated that $19 \%$ of the users never used any of the library reference services before, which means that this percentage of NCknows users are new. Whether NCknows users are new or existing library users, however, it was important to determine how users were learning about the service. This motivated the following question.

\footnotetext{
3 The interview protocol can be found online at http://purl.oclc.org/NET/POMERANTZ/NCKNOWS/ patron_followup.html.

${ }^{4}$ Note that these numbers sum to greater than $100 \%$. This is due to the fact that some users had used more than one of the other reference services offered by their library. Other purposes for which users used the library included to check books out, to bring their children for story time and other children's programs, to conduct genealogy research, and to use public access computers.
} 


\subsubsection{Discovery of NCknows}

Another follow-up interview question asked how the user had learned about the NCknows service. A total of 68 users replied to this question, by both telephone and e-mail. Four routes by which users learned about the service emerged from responses:

1. The local library, or library-produced publicity materials (47, 69\%): A librarian recommended the service to users during a physical visit to their local library, or users came across a mention of the service in materials prepared by their local library (e.g., library newsletters, flyers, Web site, or radio news coverage).

2. Online searching $(8,12 \%)$ : The user came across the service either by searching in a search engine for some topic and serendipitously retrieving a link to the service, or the user was using another Web site that contained a link to the service. These users did not know about the service until they came across it online.

3. School system $(8,12 \%)$ : The service was recommended to the user in a school setting (e.g., a college orientation, mentioned by a teacher or professor in class, or a link from a school's Web site).

4. Friends and colleagues $(5,7 \%)$ : Users had the service recommended to them by another individual who knew about the service (e.g., a friend, classmate, or someone on a listserv to which the user subscribes).

\subsubsection{Motivation for using the service}

The question as to users' previous use of other reference services had a follow-up question that concerned the user's motivation for using NCknows rather than any of the other available reference services. A total of 68 users, among them five librarians, replied to this question. Seven overarching categories of motivation emerged from users' responses:

- Convenience $(32,47 \%)$ : Users used NCknows because of their perception that chat reference service is fast, efficient, and questions may be answered immediately; that the service is easy to use, always available, and accessible from any computer with Internet access, unrestricted by physical location; and users found it to be less trouble than other forms of reference service.

- Other means of seeking information were not helpful (10, 15\%): Before trying NCknows, users had already used other means to search for information but did not get their questions answered by those means.

- Curiosity $(9,13 \%)$ : Users were curious about the service and wanted to try it out.

- Serendipity (8,12\%): Users came across the service online, often via a search engine, thought it might be useful in answering their questions, and gave it a try.

- Recommended by others $(5,7 \%)$ : NCknows was recommended to the user by another user or reference service. The user chose to use NCknows because of this recommendation.

- Personal characteristics/habits (5, 7\%): Users chose to use NCknows due to some personal characteristic or habit, such as English not being the user's native language, shyness, or an affinity for computers. 
- Other reference services were not available (1, 1.5\%): One user used NCknows because other reference services were not available at the particular moment that she was seeking information.

Some of these categories naturally overlap: one user, for example, indicated that he was unable to find the information he was seeking via other means, came across NCknows serendipitously, and then decided to use it out of curiosity. Another user indicated that NCknows was recommended to him by another user who apparently came across the service serendipitously.

It is worth noting that the librarians who responded to this question used the service for one of two reasons: to seek help in answering questions they had received in their own reference services, and out of curiosity. Those librarians who used the service out of curiosity, said that their library did not offer chat reference service, and they wished to report on the NCknows service to their colleagues and library directors. The follow-up interviews also identified 3 users (4\% of the total number interviewed) who used the service specifically for the purpose of testing it: a student in an MLS program, a librarian, and a library director. Most of the librarians who used NCknows were from within North Carolina. It was known within the library community in the state that the NCknows pilot was going on, and that if it was deemed successful, additional libraries would be asked to join. It is therefore a little surprise that librarians and library directors from around the state would be curious about the service and would want to find out more about it before deciding whether or not to join.

\subsubsection{Motivation for asking the question}

Users were asked about their motivation for asking the question. A total of 72 users replied and one user answered this question for two different chat sessions, bringing the total number of responses to 73. Six categories of motivation emerged from users' responses:

- To answer a work-related question (51\%): these questions concern activities, projects or problems in which the user is engaged. These questions are split fifty/fifty between business-related and school-related questions. Users who asked business-related questions were mostly businesspeople who asked questions related to a current project. Users who asked school-related questions were split between students and educators (both K-12 teachers and professors in higher education). Students asked questions related to a current course or assignment; educators asked questions both related to courses and assignments, and for purposes of planning courses or coursework.

- To answer a question that arose from the user's personal life (32\%): Questions of this type broke down into several sub-categories: Genealogy, hobbies or other activities, the pursuit of vocational or academic change, and plain curiosity.

- To conduct a known-item search (8\%): In these questions, the user either knew the name of a source but could not locate it, or the user knew the name of some piece of content contained within a source (e.g., the name of a poem or short story) but not the name of a source that contains that content. 
- To answer a question about the library itself (3\%): These questions concerned library policies or services available online.

- To help others look for information (3\%): These were imposed queries (Gross, 1998), where the questioner stated that he/she was asking on behalf of another.

- Other (3\%): Users gave no indication of the motivation of the question. All of these users responded to the follow-up interviews by e-mail.

Fig. 1 presents some examples of users' questions.

\subsection{The point of service}

Chat sessions are handled for the NCknows service by both librarians in libraries participating in NCknows and the staff of the 24/7 Reference company. Because of this, the

\section{Business-related:}

"I'm a small business owner and I need the information to negotiate with other type of business people to do a joint venture."

\section{School-related:}

"I was doing a research paper on homeschooling. Want some hard stats numbers from the website about how homeschool students do academically."

\section{Genealogy:}

"Wanted to find passenger ships of 1800 that had been lost at sea, trying to find one that may have been carrying wife and children of my great grandfather."

\section{Vocational or academic change:}

"doing research on school that meets the criteria that I'm looking for. I want to go back to school."

\section{Curiosity:}

"Every time I come across those words [Filipino and Philippine] in a newspaper, it makes me wonder [why one has one $P$ and the other has three]."

\section{Known-item search:}

"I was looking for an audio book and couldn't understand the new system."

\section{About the library:}

"I thought it's inconvenient for me to go to the library each time for a request for an interlibary loan. It would be nice to do it over the internet."

\section{On behalf of others:}

"It was my son's schoolwork questions in Geography class. He had found the answers to many of his geography questions but we had searched and searched using Google and also used Ask Jeeves but were not successful in finding the answers to a couple of questions."

Fig. 1. Examples of users' questions. 
exit surveys naturally include responses from users who chatted with both NCknows librarians and 24/7 staff. Of all exit surveys:

- $37.2 \%$ of responses are from users who chatted with NCknows librarians,

- $19.3 \%$ chatted with 24/7 Reference staff,

- $13.7 \%$ chatted with both, and

- $29.7 \%$ were indeterminate.

The $13.7 \%$ of users who chatted with both NCknows librarians and 24/7 Reference staff were disconnected or logged out, and then reconnected to NCknows right away and were picked up by a different librarian. The $29.7 \%$ of exit surveys that were indeterminate were so because, as mentioned above, the research team was able to manually link only $70 \%$ of the exit survey responses to chat session transcript numbers.

That users chatted with NCknows librarians almost twice as frequently as with $24 / 7$ staff reflects two facts about the NCknows service. First, the greatest volume of users used the service during NCknows' hours of service. The hours during which librarians from the participating libraries staff the NCknows service is 10 AM to 8 PM on weekdays, and 1-6 PM on weekends; $73 \%$ of NCknows users connect during these hours of service on weekdays, and $40 \%$ on weekends. Weekends, however, account for only $18 \%$ of the total volume of sessions received by NCknows. Thus, given the hours that NCknows librarians are staffing the service and the patterns in incoming traffic, there is more opportunity for a user to chat with an NCknows librarian than a 24/7 employee. Second, one of the terms of NCknows' contract with 24/7 dictates that, during NCknows' hours of service, 24/7 staff cannot "pick up" a user until 90 seconds after the user has logged in. This agreement is an attempt to ensure that NCknows librarians will chat with as many NCknows users as possible, but that if NCknows librarians are very busy, users will be picked up by $24 / 7$ staff.

Table 1 presents data on measures of users' satisfaction with various aspects of the NCknows service. The user has not had sufficient time to use the information provided by the librarian so can only evaluate the reference service on the basis of immediate impressions. It is the limitation of these immediate impressions as evaluation metrics for reference work that led to the research team conducting follow-up interviews. Because the overarching project was an evaluation effort of the NCknows service, however, it was necessary to establish that users were satisfied with their interaction with the service.

Note that users' satisfaction on all of these measures is high. People tend, when reporting on their satisfaction with a service, to be generous, especially when that service is provided by

Table 1

Users' satisfaction on aspects of the chat service $(n, \%)$

\begin{tabular}{lcccc}
\hline & Satisfaction & Speed & Helpfulness & Ease of use \\
\hline Very satisfied & $265,68.48 \%$ & $258,67.72 \%$ & $310,81.15 \%$ & $320,82.69 \%$ \\
Satisfied & $91,23.51 \%$ & $95,24.93 \%$ & $50,13.09 \%$ & $55,14.21 \%$ \\
Dissatisfied & $21,5.43 \%$ & $20,5.25 \%$ & $13,3.40 \%$ & $7,1.81 \%$ \\
Very dissatisfied & $10,2.58 \%$ & $8,2.10 \%$ & $9,2.36$ & $5,1.29 \%$ \\
\hline
\end{tabular}


another human being with whom the respondent has had some personal contact. This is one explanation for why reports of user satisfaction with reference services is so high, even when users report that the answer provided by the service was not complete (see, for example: Durrance, 1989; Richardson, 2002). This may also be the case here.

When users were asked to rate the speed of the service, their subjective perception played an important role. Of 256 users who rated the service as "very quick", 148 chat sessions were able to be linked to their transcript numbers; the average length of these sessions was 20.2 minutes. Only 3 transcripts could be identified for which users rated the service as "very slow"; the average length of these sessions was 24.7 minutes. Due to the small sample size of "very slow" ratings, no statistical analysis is possible to determine whether these two groups of users are significant different. But users' narrative responses indicate that the definition of quick and slow is largely a subjective perception.

Table 2 presents the results from an alternative measure of satisfaction, the user's willingness to recommend the service. NCknows scored very high on this measure. The willingness to recommend something - a product, a service, etc. - is a high bar; people are generally willing to complain in public but tend to be positive less often (International Customer Service Association, 2005; Society of Consumer Affairs Professionals in Business, 2003). The fact that the overwhelming majority of respondents are very likely to recommend NCknows is a credit to the service.

\subsubsection{Role of the user}

Table 3 presents demographic information about the user. It was important, in this evaluation effort during NCknows' pilot phase, to determine the composition of the service's primary user communities. These data will assist the librarians providing the service to conduct reference transactions appropriate to the user, and it will also impact the marketing of the service after its launch. Combining the student categories accounts for $47 \%$ of all users, and combining the educator categories (Teacher, Faculty, Librarian) accounts for $18.6 \%$ of all users. The "other" category unfortunately accounts for the largest category of users; nearly a third $(32.7 \%)$ of users who specified "other," however, also provided an alternative role. Among these were genealogist (19.4\%), retired (13.9\%), active readers (11.1\%), unemployed $(8.3 \%)$, legal worker (5.5\%), and business person (5.5\%). Other "other" categories specified by only one or two users included artist, journalist, volunteer, grant evaluator, medical patient, church worker, and grandparent.

As discussed above, students accounted for nearly half of all NCknows users. Students are also the largest group of users that had used the information provided to them by NCknows by

Table 2

Users' willingness to recommend the chat service

\begin{tabular}{lcc}
\hline Recommend & Number & Percentage \\
\hline Very likely & 337 & 87.53 \\
Maybe & 39 & 10.13 \\
Unlikely & 6 & 1.56 \\
Never & 3 & 0.78 \\
\hline
\end{tabular}


Table 3

Role of the user

\begin{tabular}{lcc}
\hline Role & Number & Percentage \\
\hline Other & 110 & 29.65 \\
Student: undergraduate & 86 & 23.18 \\
Student: graduate & 50 & 13.48 \\
Parent & 29 & 7.82 \\
Student: K-12 & 27 & 10.34 \\
Librarian & 20 & 7.66 \\
Teacher: K-12 & 13 & 3.59 \\
Administrator & 10 & 2.70 \\
Higher education faculty & 9 & 3.45 \\
Adult educator & 8 & 3.07 \\
Medical professional & 6 & 6.25 \\
Teacher: pre-school & 3 & 0.81 \\
Policymaker & 0 & 0.00 \\
Politician & 0 & 0.00 \\
\hline
\end{tabular}

the time of the follow-up interview. This breaks down further as follows: of the users who had used the information provided, $18.6 \%$ were graduate students and $9.3 \%$ were undergraduates. The fact that students are the group that most immediately used the information provided may indicate that students seek information close to their immediate point of information need (for example, at the last minute before an assignment is due). The same might be said of administrators, who accounted for $11.6 \%$ of users who had used the information provided.

Students are the largest group of users that had used the information provided by the time of the follow-up interview. Undergraduate students are also one of the largest groups that had not used the information provided (17.6\%). Undergraduates form a bimodal distribution: those who used the information provided quickly, or not at all. One possible explanation for this bimodality is that some undergraduates may seek information at the last minute before an assignment is due and then use that information quickly, whereas others may change the direction of their research after having already sought some information on a topic.

Interestingly, the librarians who used the NCknows service were one of the largest groups of non-users of the information provided (17.6\%). All of these librarian-users interviewed were from libraries other than the 18 participating in NCknows, and as discussed above, used the service for one of two reasons: to learn more about the service itself by using it, or to seek help from other librarians to answer questions they had received in their own reference services. The term "use" here is ambiguous: in the former case, the librarian-user was experimenting with the service, asking a question that did not necessarily reflect a genuine information need. Instead, the librarian-user's information need was fulfilled by the use of the service rather than the information provided by the service, so they may have had no need to actually use the information provided. In the latter case, the librarian-user was asking an imposed query, and so they were not the ultimate end-user of the information; the librarian- 
user may not have interpreted passing information along to the end-user as "use" of the information.

\subsubsection{Users' comments}

The exit survey contained the typical end-of-survey question, an open-ended question to elicit any additional comments from the user about the service. Users' additional comments are mainly related to the various aspects of the service and reiterate their satisfaction or dissatisfaction with the service. These additional comments will be presented here simply as positive and negative.

Mon and Janes (2003) counted unsolicited "thank you" messages received in response to answers provided to e-mail questions received by the Internet Public Library, and report a 20\% "thank you rate." The additional comments provided by NCknows users showed a 13.4\% thank you rate, counting only those comments in which the user used the words "thank you" or "thanks" or a number of misspellings of those words (e.g., "thank-you" or "thanx"). Counting those comments in which the user made other positive comments (such as about the speed or efficiency of the service, or the helpfulness of the librarian, or how great the service is), the additional comments show a 74.6\% "positive comment rate." The additional comments also show a $27.6 \%$ "negative comment rate." The percentages of positive and negative comments sums to greater than $100 \%$ because many comments were mixed. Fig. 2 presents some

Positive comments:

"wonderful idea you have here!!!!!!"

"I told my kids about it the first chance I got. Now we'll have to see how often we can come up with questions we can't answer by ourselves."

\section{Negative comments:}

"I felt a little rebuffed when the operator told me she had two other people she was working with. That response made it seem as if what I wanted was not important."

"I was booted from the chat prior to closing. I am not sure if I did it or the system kick me out."

\section{Mixed comments:}

"I found the reference librarian to be extremely knowledgeable and interested in helping me. I appreciate that very much. However, I found the chat experience rather confusing and I wasn't clear what I should be looking at or when I should click or type something."

"I'm glad you have this service, it will be great for NC residents. I just wanted to comment that the wait time between answers seemed a bit slow. Maybe that's a function of the software you are using or maybe your librarian is just getting used to it. You might want to explore getting the software to operate a little faster or adding something like the librarian is typing or something like that so people know that the answer is coming."

Fig. 2. Users' additional comments on the exit survey. 
examples of the more glowing of the positive, the more critical of the negative, and the most thoughtful mixed comments.

Two overarching themes emerged from the users' comments. These themes are likely to be familiar to all reference librarians: the interaction between the user and the librarian and the usability of the software. These are the primary issues that affect users' immediate impressions of the reference service. As discussed above, however, immediate impressions are limited as evaluation criteria, so follow-up interviews were conducted to collect data about the users' use of the information provided by the service.

\subsection{Use of the information provided by the service}

One of the questions on the follow-up interview concerned whether and how the user had used the information provided by the librarian in response to the question. A total of 67 users provided replied to this question. One user answered this question for two different chat sessions, bringing the total number of responses to 68 . Three categories of use emerged from users' responses:

1. Use: by the time they were interviewed, the user had used the information provided (63\%).

2. Partial use: the user had used the information provided and had found it partially useful, or the user had partially used the information provided $(12 \%)$.

3. No use: the user had not used the information provided at all (25\%).

Users who had used the information provided stated that the information helped them in accomplishing one of five types of tasks:

1. Work-related uses: the information provided filled in a gap in the user's knowledge that allowed her to accomplish a business-related or a school-related task $(69 \%(n=22)$ were business related tasks, $31 \%(n=22)$ were school related tasks).

2. Personal uses: the information provided filled in a gap in the user's knowledge that allowed her to achieve a personal goal $(33 \%, n=43)$.

3. Found a known item: the information provided allowed the user to find the specific information source or piece of information for which she was searching $(7 \%, n=43)$.

4. Helping others: only two respondents used NCknows because they were helping other people seek information, but three $(7 \%, n=43)$ said that they shared the information that they received with others.

5. In one case $(2 \%, n=43)$ the user simply pointed out that he used the information provided, but did not provide details as to how.

These above uses, as might be expected, mirror users' motivations for asking a question. This may be the ideal situation for a reference service or indeed any service that provides information: that the information provided actually fulfills the information need that motivated the use of the service. Not all users, however, had had the opportunity or motivation to fully use the information provided. 
Users who had partially used the information provided stated that there were three reasons why this was so:

- the user had gone to the information source provided and found this source to be unhelpful;

- the user's question was not fully answered, but relevant information sources or useful leads were provided, so that the user believed that a complete answer might ultimately result with more research; and

- the user had not yet found the time to fully use the information provided, but what had already been used was useful.

$\Lambda^{\text {Users whe had not used the information provided stated that there were three reasens why }}$ net:

- The user had not yet had a chance to use the information provided, because they had not yet gotten to the stage in their work where they needed it.

- The information was provided too late, after the user no longer needed it. As might be expected, this issue was raised only by users for whom the librarian could not provide a complete answer during the chat session. In such cases, librarians asked for the user's e-mail address and followed up some time later by e-mail with more information.

- The information provided did not fulfill the user's information need or the user's question was not answered. The information provided was either entirely incorrect, or insufficient in breadth or depth to satisfy the user. There were two causes for the question not being answered: the user's question was so difficult or specific that the librarian was unable to find a complete answer or any answer at all, and limitations in access to fee-based services

\section{Use:}

"It was utilized as background information for my lecture."

"I used the information in the negotiation with other business owners.

Through the knowledge gained, we have (hopefully) brought another business to Fayetteville. At least we are talking now."

\section{Partial Use:}

"NCknows told me the person to call at my local library who said they can't provide that information. I was going to use it in my graduate school thesis. Alas..."

"I am still working on this matter but was provided good leads from your service."

No use:

"The librarian did give me a website for on loan tapes, but they took to [sic] long to receive."

"I plan to call the number I got from the service in a couple of time." [sic]

Fig. 3. Examples of users' comments on their use of the service. 
limited what the librarian could provide to the user. An example of this latter case is that a librarian and a user on the same university campus would have access to the same set of database subscriptions, whereas an off-campus user would not have the same access. In these cases, librarians relied more heavily on resources on the free Web, which naturally restricted the breadth and depth of information that the librarian was able to provide on certain topics.

Fig. 3 presents some examples of users' comment on their use of the information provided to them.

\section{Discussion}

\subsection{Non-response bias}

Both the exit survey and the follow-up interviews suffered from low unit response rates: $8.6 \%$ of NCknows users who came into the service via queues other than PLCMC's, submitted the exit survey, and $18.6 \%$ of users who submitted the exit survey (1.6\% of all NCknows users) were interviewed. As a result of this, it is imperative to investigate the effect of unit nonresponse bias on these results.

One method for investigating the effect of non-response is to collect data from the nonrespondents to enable a comparison between the respondents and the non-respondents according to relevant characteristics. It was unfortunately not possible for the researchers to conduct such a comparison. There are two types of non-respondents in this study: NCknows users who did not submit an exit survey, and users who submitted an exit survey but were not willing to be contacted for a follow-up interview. It was impossible for the researchers to reach many of the former category of users; it would have been illegal to contact the latter category of users.

The NCknows service asks, but does not require, users to submit their e-mail address when they connect to the service. If an e-mail address is provided, the $24 / 7$ application e-mails a copy of the chat transcript to the user. Because it is not required, only $72 \%$ of users do in fact provide an e-mail address. Of these, a percentage are likely to be invalid, either because the user deliberately submits a fake e-mail address, or because the user accidentally makes a typo. It is not known what percentage of the e-mail addresses submitted by users is invalid because NCknows does not validate these addresses; however, $4 \%$ of the e-mail addresses provided by users on the exit survey were different from the e-mail address provided by the same user when they connected to the service. The non-respondents for the exit survey fall into two categories: users who submitted a valid e-mail address when they connected to the service and users who did not. Users who did not submit a valid e-mail address were of course impossible to contact.

It would seem, however, that it would be possible to contact those users who did submit a valid e-mail address when they connected to the service. This is true technically (i.e., the researchers had a valid e-mail address at which to contact the user) but not legally. These users could not be contacted according to the requirements of the institutional review board at the 
authors' institution. According to these requirements, any study involving human subjects must allow participants to opt out of the study at any time nith ill consequences. Because the exit survey was Web-based, the researchers could not collect a signed consent form from the user. Instead, the exit survey itself became the consent form, by including the following statement: "Clicking the Submit Form button at the end of this survey constitutes consent to participate in this study." If the user did not submit an exit survey, that must therefore be taken as a refusal to consent to participate in the study. The users who opted out of the exit survey could not, according to the institutional review board's requirements, thereafter be contacted for any other reason.

Similarly, users who opted out of the follow-up interviews could not be contacted. As discussed above, the final two questions on the exit survey ask the user if she would be willing to be contacted for a follow-up interview, and asked for the user's e-mail address. Of the users who submitted an exit survey, $72.5 \%$ indicated that they were willing to be contacted for a follow-up interview. These users were of course contacted. The remaining $27.5 \%$ of users, however, by indicating unwillingness to be contacted, had opted out of the study. Thus, due to both technical and legal reasons, it was impossible to assess the effect of non-response bias on the results of the exit survey and the follow-up interviews, by collecting data from the non-respondents.

Another method for investigating the effect of non-response is to compare respondents and non-respondents according to those characteristics that are known about each group. Nothing is known about those users who did not submit an exit survey, except what they submitted when they connected to the service (a deliberately minimal set of data, including the user's name, e-mail address, zip code, and question, all of which are optional), and what they divulged in the chat session itself.

Considerably more is known about users who submitted an exit survey but were not willing to be contacted for a follow-up interview. The chi-square statistic was used to determine whether there were any significant differences in responses to questions on the exit survey, between those users who agreed to be contacted for a follow-up interview and those who did not. Significant differences were identified for three of the exit survey questions: the user's satisfaction with the completeness of the answer, the helpfulness of the librarian, and the speed of the service $\left(\chi^{2}=14.33, d f=3, n=373, p=0.002 ; \chi^{2}=10.62, d f=3, n=366, p=0.003\right.$; and $\chi^{2}=14.29, d f=3, n=368, p=0.014$, respectively). Users who were willing to be interviewed evaluated the service provided by NCknows significantly more positively than users who were unwilling to be interviewed. One possible explanation for this is that users who were unsatisfied with the service might be disinclined to talk about it further, whereas users who were satisfied might be more willing to share this with the evaluation team. This interpretation actually flies in the face of the findings by the International Customer Service Association (2005) and the Society of Consumer Affairs Professionals in Business (2003), which both found that dissatisfied customers are significantly more likely to talk about their negative experience with a company or a service than satisfied customers are to talk about their positive experience. Those studies, however, are concerned with word-of-mouth marketing and investigated customers' communication with friends, colleagues, and the like and not with the companies themselves. The findings of the present study may indicate that users are willing to 
communicate their satisfaction or dissatisfaction to differing degrees, depending on with whom that communication is being conducted.

\subsection{Self-selection bias}

There is a further methodological problem faced by exit surveys: the users who submit exit surveys are self-selected. Even though the exit survey pops up at the completion of every chat session, the user must voluntarily fill it out and submit it. There is no way to force users to do this. After having just spent time in the chat session itself (an average of 14.6 minutes for NCknows sessions), many users are apparently unwilling to spend even an extra minute or two filling out a survey.

Though there is no evidence to support the assertion that this is the case, the possibility that the exit survey respondents are significantly different from non-respondents along some dimension cannot be ruled out. Respondents therefore may not be representative of the general user population of NCknows, or of the population of users of chat reference services in general. Because, as discussed above, there is no way to obtain data from users given the existing methodological constraints other than by allowing users to self-select, the demographics of NCknows' user population are unknown. Indeed, the only characteristic of this population that is known for certain is the use of NCknows. Further, while there have been many studies of the user populations of individual digital reference services, there have been no studies of the user populations of digital reference services in general. The lack of data about this overarching user population calls out for future research to determine the "demographics" of the population of digital reference service users.

It should be pointed out that exit surveys for other services do not have much better response rates than this study's 8.6\%: Hill et al. (2003) report a 14.2\% response rate, whereas Marsteller and Neuhaus (2001) report an approximately 20\% response rate to "at least part of the survey," indicating that they too encountered unit non-response. Ruppel and Fagan (2002) do not report their response rate, but they do report that they received 340 exit survey responses. They also report an average of 9.5 questions per day for the semester in which they conducted their study; for a 16-week semester (including reading and finals periods) this allows the estimation of a $32 \%$ response rate.

\subsection{Discussion of findings}

Two recent studies of users of chat reference services asked respondents what reference and other library services they had used previously to seek help (Horowitz et al., 2005; Johnson, 2004). These studies used different categories of library services and so are not directly comparable. Some categories did overlap, however, and also overlap with the categories used in the present study. All three studies found that when users had used another reference service, the most common form used was desk reference, followed distantly by telephone, and use of an e-mail service and no previous use of any reference service were roughly tied for third place. While the percentages of the user population found by these three studies do not match, the rank order of these categories of previous use is identical. 
The motivation for asking users whether they had ever used any of the other reference services offered by their library was to determine if NCknows users were the same individuals who used other library reference services, or if NCknows was reaching new user communities. The majority of interviewees were already users of other forms of reference service, but nearly $20 \%$ had never used any other reference service. An interesting avenue for future research will be to determine the effect of marketing campaigns for the NCknows service on the percentages of existing and new users.

Campaigns to market chat reference services should be targeted to user groups that are likely to have a need for the service, such as in grade schools, colleges, and universities; businesses and other corporate settings; and social organizations. Johnson (2004) found that the largest group of users of the service he studied was undergraduates, followed by graduate students, with faculty as the smallest user group. This is echoed by the findings in Ciccone and VanScoy's study (2003). Other evaluation studies of chat reference services also reported that students (both undergraduates and graduates) are the largest group of users (Curtis \& Greene, 2004; Kibbee, Ward, \& Ma, 2002; Lee, 2004; Marsteller \& Neuhaus, 2001) The present study offered the respondents more categories for their role in the use of the service, but again, the rank order of these categories of the users' roles are identical with the above studies. Johnson, too, suggests that chat reference services may benefit from marketing efforts; these findings indicate which user groups a service might wish to target in marketing campaigns.

Horowitz et al. (2005) report that the single greatest reason why users used the service was its convenience: users did not want to or could not physically come to the library, and users believed that the service could provide them with information rapidly. This was the reason given by approximately $50 \%$ of all users that responded both to Horowitz, Flanagan, and Helman's and the present study's surveys. The availability of the service at all hours of the day and night is one factor in the convenience of the service. Horowitz, Flanagan, and Helman suggest several more, including that the software be simple to use, and that it work well across diverse networks.

Recall that the follow-up interviews, whether they were conducted by telephone or e-mail, took place two to three weeks after the user's chat session. The authors had judged this to be an adequate amount of time for users to have made use of the information obtained from NCknows. The fact that a percentage of users had not used the information provided to them after two to three weeks indicates that there is a set of users who are planning very far ahead, and seeking information considerably in advance of their point of need. This raises the question of whether using a chat reference service (that is, a synchronous medium) is the best option for these users. It may be that an e-mail service would be preferable, as e-mail is asynchronous and these users clearly can afford to wait, if the payoff is that the librarian will be able to spend more time formulating an answer and provide greater breadth and depth of information.

This raises the question of what media is most appropriate for what types of reference service, and how to encourage users to use a reference service in the most appropriate medium. Horowitz et al. (2005) report that a majority of users believe that chat is a useful medium for simple questions. Kern (2003), however, reports that requests for research assistance are 
highest in chat services. It thus appears that there may be a mismatch between users' expectations of chat reference services and what these services are actually able and best suited to provide. This too may be an area where chat reference services may benefit from improved marketing efforts. It will be necessary, however, before chat reference services may market themselves as vehicles for specific types of assistance, for librarians to identify what types of assistance really are best suited by chat or other types of reference services.

\subsection{Methodological enhancements}

In future research, more effort needs to be devoted to solving the methodological issues involved in recruiting users as study subjects in order to make the sample more representative of the population of digital reference users. Other possible recruiting methods might be considered for use. For example, instead of asking whether the user is willing to have a followup interview in the exit survey, a follow-up survey could be automatically e-mailed to users after two weeks. Alternative methods for recruiting subjects would need to be tried to determine what garners the best response rate without violating users' privacy.

Another interesting area of research is the question of what users gain from using the information provided by a reference service. For example, do they find uses of the information other than the original intended use? Are there physical or psychological benefits brought by application of the information? Answers to these questions would provide a way to further quantify the value and utility of the information or the service.

\section{Conclusion}

This study combines traditional evaluation methods of the user's satisfaction with the reference encounter, with a new approach made possible by the online nature of the service: elicitation of the user's information use and motivation for using the chat reference service. This analysis of users' motivations for seeking and use of information facilitates understanding of the complete process of reference interactions: motivations as prior to a reference session and usage as an extension of it. Placing the evaluation within the context of a user's information need and how it has been fulfilled allows a holistic assessment of the value of chat reference services.

This combination of methodologies may serve as a model for evaluation of online reference services, and reference services in general: an exit survey to elicit the user's immediate satisfaction with the reference transaction, and a follow-up interview to elicit data about the user's actual use of the information and how that information fulfilled the user's information need. The major issue that needs to be addressed for this methodology to be truly useful is that of non-response: a method for eliciting a greater response rate on both exit surveys and follow-up interviews needs to be developed. Once this is developed, the methodology presented here, in combination with other evaluation methods and metrics, will enable a broad and deep evaluation of the context, performance, and impact of reference service. 


\section{Uncited references}

Glaser \& Strauss, 1967

Hernon \& McClure, 1986

Pomerantz et al., in press

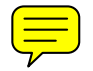

Reference and User Services Association Access to Information Committee, 2004

\section{Acknowledgments}

The authors wish to extend thanks to several individuals and groups. To Jeanne Crisp, Phil Blank, and the State Library of North Carolina's Virtual Reference Advisory Committee for allowing the authors this opportunity to work on the evaluation of the NCknows service. To all of the librarians participating in NCknows, for taking the time to participate in this evaluation effort. And to Charles McClure for his invaluable assistance in conducting this evaluation effort.

\section{References}

Ahituv, N. (1980). A systematic approach toward assessing the value of an information system. MIS Quarterly, 4(4), 61-75.

Broadbent, M., \& Lofgren, H. (1993). Information delivery: Identifying priorities, performance, and value. Information Processing \& Management, 29, 683-702.

Ciccone, K., \& VanScoy, A. (2003). Managing an established virtual reference service. Internet Reference Services Quarterly, 8(2), 95-105.

Coffman, S., \& Arret, L. (2004). To chat or not to chat: Taking another look at virtual reference, Part 1. Searcher, 12(7), 38-49. Retrieved November 16, 2005, http://www. infotoday.com/searcher/jul04/arret_coffman.shtml

Coffman, S., \& Arret, L. (2004). To chat or not to chat: Taking yet another look at virtual reference, Part 2. Searcher, 12(8), 49-56.

Crowley, T. (1971). The effectiveness of information service in medium size public libraries. His information service in public libraries: Two studies (pp. 1-96). Metuchen, NJ: The Scarecrow Press.

Curtis, D., \& Greene, A. (2004). A university-wide, library-based chat service. Reference Services Review, 32, 220-233.

Davis, S., \& Wiedenbeck, S. (2001). The mediating effects of intrinsic motivation, ease of use and usefulness perceptions on performance in first-time and subsequent computer users. Interacting With Computers, 13, 549-580.

Dervin, B. (1983, May). An overview of sense-making research: concepts, methods, and results to date. Paper presented at the annual meeting of the International Communication Association, Dallas, TX.

Dervin, B. (2003). From the mind's eye of the user: The sense-making qualitative-quantitative methodology. In B. Dervin, L. Foreman-Wernet, \& E. Lauterbach (Eds.), Sense-making 
methodology reader: Selected writings of Brenda Dervin (pp. 270-292). Cresskill, NJ: Hampton Press.

Durrance, J. C. (1989). Does the 55 percent rule tell the whole story? Library Journal, 114(7), 31-36.

Glaser, B. G., \& Strauss, A. L. (1967). The diseovery of grounded theory. Strategies for quatitu research. Chicago: Aldine Publishing Company.

Gross, M. (1998). The imposed query: implications for library service evaluation. Reference \& User Services Quarterly, 37, 290-299.

Gross, M. (1999). Imposed versus self-generated questions: implications for reference practice. Reference \& User Services Quarterly, 39(1), 53-61.

Hernon, P., \& MeClure, C. R. (1986). Unobtrusive reference testing: the 55 percent rule. Library Journal, 111(7), 37-41.

Hill, J. B., Madarash-Hill, C., \& Bich, N. P. T. (2003). Digital reference evaluation: assessing the past to plan for the future. Electronic Journal of Academic and Special Librarianship, 4 (2-3). Retrieved June 24, 2005, from http://southernlibrarianship.icaap.org/content/ v04n03/Hill_j01.htm

Hirko, B. (2004). VET: The virtual evaluation toolkit. Olympia, WA: Washington State Library.

Horowitz, L. R., Flanagan, P. A., \& Helman, D. L. (2005). The viability of live online reference: An assessment. Portal: Libraries and the Academy, 5, 239-258.

International Customer Service Association. (2005). Benchmarking study of electronic customer care. International Customer Service Association.

Johnson, C. M. (2004). Online chat reference: Survey results from affiliates of two universities. Reference \& User Services Quarterly, 43, 237-247.

Kaske, N., \& Arnold, J. (2002). An unobtrusive evaluation of online real time library reference services. Retrieved June 24, 2005, from http://www.lib.umd.edu/groups/digref/ kaskearnoldunobtrusive.html

Kern, M. K. (2003, June). What are they asking? An analysis of questions asked at in-person and virtual service points. Paper presented at the ALA Annual Conference, 9th Annual Reference Research Forum, Toronto, Ontario, Canada.

Kibbee, J., Ward, D., \& Ma, W. (2002). Virtual service, real data: Results of a pilot study. Reference Services Review, 30(1), 25-36.

Lee, I. J. (2004). Do virtual reference librarians dream of digital reference questions?:A qualitative and quantitative analysis of email and chat reference. Australian Academic \& Research Libraries, 35(2), 95-109.

Marchant, M. P. (1991). What motivates adult use of public libraries? Library \& Information Science Research, 13, 201-235.

Marsteller, M.R., \& Neuhaus, P. (2001). The chat reference experience at Carnegie Mellon University. Retrieved June 24, 2005 from http://www.contrib.andrew.cmu.edu/ matthewm/ ALA_2001_chat.html

McClure, C. R., Lankes, R. D., Gross, M., \& Choltco-Devlin, B. (2002). Statistics, measures and quality standards for assessing digital reference library services: Guidelines and procedures. Syracuse, NY: Information Institute of Syracuse. 
Mitchell, T. R. (1982). Motivation: New directions for theory, research, and practice. Academy of Management Review, 7(1), 80-88.

Mon, L., \& Janes, J.W. (2003). The thank you study: User satisfaction with digital reference service. Retrieved June 24, 2005 from http://www.oclc.org/research/grants/reports/janes/ jj2004.pdf

Murfin, M. E. (1993). Cost analysis of library reference services. Advances in Library Administration and Organization, 11, 1-36.

Pomerantz, J. (2004). A repeated survey analysis of AskERIC user survey data, 1998-2002. In R. D. Lankes, J. Janes, L. C. Smith, \& C. M. Finneran (Eds.), The virtual reference experience: Integrating theory into practice (pp. 11-41). New York: Neal-Schuman.

Pomerantz, J., Luo, L., \& MeClure, C.R. (fortheoming). Peer review of chat reference transeripts: Appreaches and strategies. Library \& Information Science Research.

Reference and User Services Association Access to Information Committee. (2004). Guidetines for implementing and maintaining virtual reference semvies. Retrieved June 24, 2005 , from http://ww.ala.org/ala/rusa/rusaprotools/referenceguide/virtrefouidelines.htm

Richardson, J. V., Jr. (2002). The current state of research on reference transactions. In F. C. Lynden (Ed.), Advances in Librarianship, vol. 26. (pp. 175-230). New York: Academic Press.

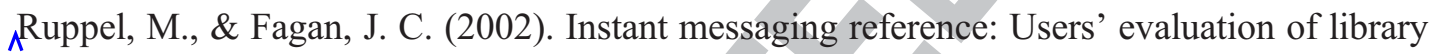
chat. Reference Services Review, 30(3), 183-197.

Saracevic, T., \& Kantor, P. B. (1997). Studying the value of library and information services. Part II. Methodology and taxonomy. Journal of the American Society for Information Science, 48, 543-563.

Saxton, M. L., \& Richardson, J. V., Jr. (2002). Understanding reference transactions: Transforming an art into a science. Amsterdam, NY: Academic Press.

Scriven, M. (1991). Evaluation thesaurus, 4th ed. Newbury Park, CA: Sage Publications.

Shapira, B., Kantor, P. B., \& Melamed, B. (2001). The effect of extrinsic motivation on user behavior in a collaborative information finding system. Journal of the American Society for Information Science \& Technology, 52, 879-887.

Society of Consumer Affairs Professionals in Business. (2003). SOCAP customer contact study: Contact channel use in customer relations. Alexandria, VA: Society of Consumer Affairs Professionals in Business.

$\mathrm{Su}$, L. T. (1992). Evaluation measures for interactive information retrieval. Information Processing \& Management, 28, 503-516 $\wedge$ 